\title{
APLICACIÓN E INFORMACIÓN DEL DERECHO EXTRANJERO EN EL ÁMBITO INTERAMERICANO, REGIONAL Y EN EL URUGUAY
}

\section{A APLICAÇÃO E A INFORMAÇÃO DO DIREITO ESTRANGEIRO NO ÂMBITO INTERAMERICANO, REGIONAL E NO URUGUAI}

Eduardo Tellechea Bergman

Resumen: El actual incremento de las relaciones privadas internacionales consecuencia, entre otras variables, del desarrollo de los medios de comunicación internacional en sus distintas modalidades $y$ de una paralela flexibilización de las fronteras nacionales, es determinante a nivel jurisdiccional del planteo de diversas cuestiones vinculadas a la aplicación e información del derecho extranjero, que el presente trabajo aborda en su regulación a nivel interamericano y regional, así como en el Derecho Internacional Privado uruguayo.

Resumo: $O$ atual incremento das relações privadas internacionais conseqüência, entre outras variáveis, do desenvolvimento dos meios de comunicação internacional nas suas diferentes modalidades e de uma paralela flexibilização das fronteiras nacionais, é determinante a nível jurisdicional a proposta de diversas questões vinculadas à aplicação e informação do direito estrangeiro, que o presente trabalho aborda na sua regulação a nível interamericano e regional, bem como no Direito Internacional Privado uruguaio.

Palabras clave: Derecho extranjero, Aplicación, Interpretación, Información, TratadosdeMontevideo, CódigodeBustamante, Convenciones Interamericanas, Protocolo de Las Leñas, Código General del Proceso de Uruguay

Palavras-chave: Direito Estrangeiro, Aplicação, Interpretação, Informação, TratadosdeMontevidéu, Código de Bustamante, ConvençõesInteramericanas, Protocolo de Las Leñas, Código Geral de Processo do Uruguai

* Doctor en Derecho. Catedrático de Derecho Internacional Privado y Director del Instituto Uruguayo de Derecho Internacional Privado, Facultad de Derecho de la Universidad de la República. Ex Director de la Autoridad Central de Cooperación Jurídica Internacional de Uruguay. 


\section{INTRODUCCIÓN}

El desarrollo de las relaciones privadas internacionales y el predominio de regulaciones convencionales y de fuente nacional que responden a una metodología conflictualista suscita un creciente número de situaciones jurídicas en las que el foro actuante se enfrenta a la necesidad de aplicar derecho extranjero. Cuestión de la que emergen interrogantes referidas a como dicho derecho deberá traerse a juicio, como deberá ser interpretado, la recurribilidad de los fallos dictados en tales casos y de qué modo los tribunales y otras autoridades de un Estado pueden informarse del derecho de los otros países.

\section{LA APLICACIÓN DEL DERECHO EXTRANJERO EN LOS TRATADOS CLÁSICOS REGIONALES}

Los Tratados de Montevideo y el Código de Bustamante acogieron tempranamente la denominada concepción moderna que, a diferencia de la postura tradicional ${ }^{1,2}$, supone la aplicación de oficio del Derecho

1 La posición tradicional nace en los albores del Derecho Internacional Privado con la estatutaria italiana, que restringe el alcance del aforismo "iuria novit curia" a los estatutos de la ciudad a la que pertenece el magistrado actuante y sostiene que es a los litigantes a quienes corresponde alegar y acreditar el derecho extranjero. Concepción que adquiere expresión clásica a mediados del siglo XIX con Foelix y Story, que asimilan el derecho extranjero a los hechos, lo que apareja como consecuencias: a) tener que ser invocado y probado por las partes; b) ser renunciable; c) no poder ser alegado en segunda instancia; y d) que los errores cometidos en su aplicación no sean susceptibles de los recursos previstos contra los errores de derecho. Esta posición mantiene cierto predicamento hasta avanzado el siglo XX y autores como Battifol, señalan que la norma extranjera no posee fuera del país de origen imperatividad, por lo que no corresponde su aplicación de oficio, BATIFFOL H. (1959) Traité Élémentaire de Droit International Privé. París: L. G. D. J, p. 381 y ss. En similar sentido, S. SATTA, afirma que quien se presenta ante un juez italiano indicando una norma extranjera como elemento constitutivo de su derecho, está obligado a ofrecer prueba de la existencia de esa norma, SATTA S. (1955) "Iuria novit curia". Rivista Trimestrale de Diritto e Procedura Civile, IX, p. 382.

Una importante innovación en la concepción del derecho extranjero como hecho es la "teoría del hecho notorio", planteada por W. GOLDSCHMIDT que afirma que en tanto hecho notorio, el juez debe tener en cuenta la norma extranjera aún cuando las partes no la acrediten, GOLDSCHMIDT W. (1935) La consecuencia jurídica de la norma de Derecho Internacional Privado. Barcelona: Bosch.

2 Otro criterio manejado en relación al derecho extranjero ha sido considerarlo como derecho propio. La "teoría del derecho propio" sostiene que al dotar la norma de conflicto de imperatividad al derecho foráneo lo integra al derecho nacional, pudiendo distinguirse en esta postura dos vertientes, la "teoría de la incorporación y la teoría de la recreación". La "teoría de la incorporación" considera que el magistrado incorpora la solución dada por el derecho extranjero a la mención en blanco que hace la norma de conflicto a través del punto de conexión. La norma indicada por la conexión se incorpora al texto de la norma de conflicto del juez y en consecuencia éste la debe de aplicar como derecho propio. Entendemos que esta concepción resulta criticable cuanto supone la absorción por cada derecho nacional de la totalidad de los sistemas jurídicos, siendo una condición en definitiva contraria a la esencia del DIPr., basada en el reconocimiento recíproco por los Estados de sus ordenamientos jurídicos. Si la norma de conflicto da competencia para regular a una relación jurídica a un derecho extranjero, éste se debe aplicar como tal; ver al respecto, ALFONSÍN Q. (1955) Teoría 
extranjero $^{3}$. Concepción que reconoce en la región el precedente del Proyecto de Código de Derecho Internacional Privado de Gonzalo Ramírez, antecedente directo de las soluciones de los Tratados de Montevideo de 1889, cuyo artículo 94 dispone pioneramente: "La aplicación de las leyes de un país por los tribunales de otro, en los casos en que este tratado lo autorice es de riguroso precepto, aun cuando la parte interesada no haya producido prueba sobre la existencia de tales leyes"4. Posición que abreva en conceptos nuevos para la época plasmados por la jurisprudencia alemana de 1868 del Tribunal Superior de Comercio ${ }^{5}$, acogidos luego por la legislación de tal origen en la ZPO de 1877, párrafo $293^{6}$. L'Institut de Droit International en la Sesión de

del Derecho Internacional Privado. Montevideo: Biblioteca de Publicaciones de la Facultad de Derecho y Ciencias Sociales de la Universidad de la República, p. 511 y ss.

La "teoría de la recreación" entiende que el juez al dictar sentencia en un caso internacional recrea el derecho extranjero aplicable, por lo que la norma foránea no actúa como tal, sino que da contenido a una norma del foro de igual sustancia a la de aquella. Al respecto ha dicho con razón YASSEEN M. K. (1962) "Problèmes relatifs à l'application du droit étranger". Recuil des Cours, T. 106-II, p. 499-596, que esta posición no refleja el espíritu del legislador de la norma de conflicto, ni el del juez que aplica el derecho extranjero, pues la norma de conflicto tiene como cometido designar el derecho aplicable y no incorporarlo ni nacionalizarlo, ni dar origen en el foro a una norma con el contenido del derecho extranjero. En el mismo sentido, ZAJTAY I. (1958) Contribution à l'étude de la condition de la loi étranger en Droit International Privé français. París: Ed. Pedone.

$3 \mathrm{La}$ "teoría moderna" o "de la aplicación del Derecho extranjero como Derecho", tiene origen en la escuela histórica alemana, Savigny, Puchta, etc, que al destacar la índole jurídica de la norma extranjera sienta las bases que propician su aplicación de oficio. En igual sentido, P. E. MANCINI, "De l'utilité de rendre obligatoires pour tours les États, sous la forme d'un ou de plusiers traités internationaux, un certain nombre de règles générales de droit internacional privé pour assurer la décision uniforme des conflicts entre les differentes législations civiles et criminelles", MANCINI P. E. (1874) Journal de Droit International Prive. París, p. 231, al sostener que los Estados "no pueden rehusarse legítimamente a aplicar leyes extranjeras". Esta concepción apareja como consecuencias: a) aplicación de oficio del Derecho extranjero, cualquiera que fuere la actitud procesal de las partes; b) las partes son meros colaboradores en la acreditación de la norma foránea, y si no lo hacen, el juez está obligado, igualmente, a aplicarlo cuando así correspondiere; c) irrenunciabilidad, las partes no pueden optar por no aplicar la norma extranjera cuando ésta es indicada para regular el caso; y d) recurribilidad, la no aplicación del Derecho Extranjero o su errónea interpretación da lugar a la interposición de todos los recursos previstos en el ordenamiento del foro en relación a la aplicación errónea del Derecho nacional material. Por un análisis detallado de las distintas posiciones acerca de la aplicación del Derecho extranjero y en especial de la "concepción moderna", ver TELLECHEA BERGMAN E. (1980) Tratamiento e Información del Derecho extranjero. Montevideo: FCU.

4 RAMÍREZ G. (1888) Proyecto de Código de Derecho Internacional Privado y su Comentario. Buenos Aires: Félix Lajouane Editor, p. 8.

5 Sentencia de 1868 del Tribunal Superior de Comercio que proclama: "Cuando una relación de derecho esté sometida por su naturaleza al predominio de una ley extranjera, el juez debe aplicar el derecho extranjero en cuanto le sea conocido, pudiendo fundar ese conocimiento ya en su propia ciencia, ya en la prueba suficiente que a su juicio las partes hayan practicado", citada por VICO C. (1935) Curso de Derecho Internacional Privado. Buenos Aires: Biblioteca Jurídica Argentina, p. 231.

6 ZPO alemana, párrafo 293, "El derecho extranjero, el consuetudinario y el estatutario, solo necesitarán ser probados cuando el tribunal no los conozca. Para la determinación de los preceptos de esta clase, el tribunal no queda limitado a las pruebas que produzcan las partes, está facultado para servirse de otras fuentes de conocimiento y para ordenar todo lo que conduzca al aprovechamiento de las mismas". 
Hamburgo de 1891 es coincidente con tales desarrollos y señala: "en el estado actual del derecho y las relaciones internacionales y en presencia del gran número de leyes elaboradas en los países civilizados, las pruebas de las leyes extranjeras no puede ser una cuestión de hecho abandonada a la iniciativa de las partes"7.

En consonancia con lo expuesto el Protocolo Adicional a los Tratados de Montevideo de Derecho Internacional de 1889, art. 2, solución luego repetida por el mismo artículo del Protocolo Adicional a los Tratados de Montevideo de 1940, acoge la aplicación de oficio (sin perjuicio que las partes puedan alegar y probar la existencia y contenido de la ley extranjera invocada) y en posición congruente con la anterior, confiere contra las sentencias dictadas en error del derecho extranjero todos los recursos acordados por las leyes procesales del lugar del juicio para los casos resueltos de acuerdo a sus propias normas, arts. 3 de ambos Protocolos. Cabe señalar que si bien los Protocolos emplean la expresión "ley", corresponde que la misma sea interpretada en el sentido de Derecho aplicable, incluyendo en consecuencia otras fuentes de Derecho, tales, la jurisprudencia y, en su caso, la costumbre, como señalara Q. Alfonsín .

En cuanto al conocimiento del Derecho de un Estado por los tribunales de los otros, los Protocolos Adicionales de 1889 y 1940, arts. 5 y 6 respectivamente, establecen la obligación para cada país de remitir a los demás dos ejemplares auténticos de sus leyes vigentes y de aquellas que posteriormente sancionen. Procedimiento que en la práctica se vió frustrado por la inexistencia en la época de órganos especializados encargados de la información del Derecho.

La otra codificación continental clásica sobre Derecho Internacional Privado, el Código de Bustamante de La Habana de 1928, también consagra la aplicación preceptiva de la norma extranjera, art. 408, así como el derecho de la parte que la invoque o disienta de ella a justificar su texto, vigencia y sentido, art. 409 y en materia de recurribilidad, dispone la procedencia del recurso de casación o "institución correspondiente", ante casos de "infracción, interpretación errónea o aplicación indebida de una ley de otro Estado contratante, en las mismas condiciones y casos que respecto al derecho nacional", art. 412. Para las hipótesis de ausencia o insuficiente información sobre el Derecho extranjero, el tribunal interviniente es autorizado a solicitar vía diplomática que el Estado de cuya legislación se trate informe sobre su texto, vigencia y sentido, art. 410; disposición que prefigura la concepción de que el Derecho extranjero debe aplicarse con el sentido que le otorga el ordenamiento al que pertenece, que posteriormente acogiera la Convención Interamericana sobre Normas Generales de

7 Conclusiones citadas por VICO, Op. cit., nota 5, p. 236.

8 Q. ALFONSÍN, Op. cit., nota 2, p. 493. 
Aplicación e información del derecho extranjero... Eduardo Tellechea Bergman

Derecho Internacional Privado de 1979, art. 2. A los efectos indicados los Estados se obligan a suministrarse información en el menor tiempo posible, la que deberá proceder de su Tribunal Superior o de sus Salas o Secciones, del Ministerio Público, o del Ministerio o Secretaría de Justicia, art. 411.

La doctrina latinoamericana más prestigiosa de la época fue coincidente con los desarrollos normativos del Derecho Internacional Privado regional. En Uruguay, con posterioridad a Gonzalo Ramírez, Rafael Gallinal afirmaba en sentido coincidente en 1916, "parece evidente que la ley extranjera no puede ser considerada como un hecho, sino que debe serlo como el derecho según el cual el juez debe decidir"9. Posición que en los años cincuenta desarrolla Q. Alfonsín con sólida argumentación ${ }^{10}$, constituyendo su pensamiento importante precedente considerado por la doctrina nacional en ocasión de analizar el tema con vistas a la CIDIP II ${ }^{11}$.

En la misma época, en Argentina, el pensamiento iusprivatista internacional de Goldschmidt hace escuela" y en las "Jornadas de Derecho y Relaciones Internacionales de la Universidad de Belgrano", en 1971, se concluye: "es deseable por ser justa, la aplicación de oficio de la ley extranjera competente" 13 y en Brasil, Haroldo Valladao señala, "la aplicación de ese derecho - por el extranjero - se hará como derecho en su totalidad"14. Posición compartida por los juristas venezolanos G. Parra Aranguren, J. Sánchez Covisa y Roberto Goldshmidt en su "Proyecto de Normas de Derecho Internacional Privado"15, así como por

9 GALLINAL R. (1916) Estudios sobre el Código de Procedimiento Civil - De las pruebas. Comentarios a los arts. 327 a 349. Montevideo: Barreiro y Ramos, p. 36.

10 "La investidura del juez lo obliga a administrar justicia con arreglo al derecho vigente en su propio Estado, si este derecho comprende normas de derecho internacional que señalen como aplicable un derecho privado extranjero, el juez está obligado a aplicarlo. Para cumplir con esta obligación, no es preciso que el juez conozca de antemano todo el derecho privado del mundo, basta con que de oficio pueda mover los medios oficiales que la ley o el Tratado ponen a su alcance ...", ALFONSÍN, Op. cit., nota 2, pp. 539-540.

11 Así la posición sostenida en Cátedra y en los trabajos preparatorios a la CIDIP por el maestro OPERTTI y los relatos presentados por Uruguay a las Primeras Jornadas Rioplatenses de Derecho Internacional, relato de M. SOLARI (1978) "Prueba del derecho extranjero e información sobre normas jurídicas vigentes en los países americanos". Primeras Jornadas Rioplatenses de Derecho Internacional. Montevideo: FCU, p. 53-61; y relato de TELLECHEA BERGMAN E., "Cuestiones procesales relativas a la aplicación de la ley extranjera", p. 35-51. 12 W. GOLDSCHMIDT, Op. cit., nota 1, tal como se ha señalado, desarrolla en La consecuencia jurídica de la norma de Derecho Internacional Privado, la teoría del "uso jurídico", que si bien concibe al Derecho extranjero como un hecho, al calificarlo de "notorio", es decir, "hecho sobre el que todo el mundo puede informarse de modo auténtico", modifica sustancialmente el enfoque tradicional.

13 Citada por GOLDSCHMIDT W. (1974) Derecho Internacional Privado. 2a. ed. Buenos Aires: Depalma, p. 469.

14 VALLADAO H. (1980) Direito Internacional Privado. Río de Janeiro: Biblioteca Jurídica Freitas Bastos, p. 224.

15 Proyecto art. 57, "El derecho extranjero será aplicado de oficio. Las partes podrán aportar informaciones relativas al derecho extranjero aplicable y los tribunales podrán dictar providencias encaminadas al mejor conocimiento del mismo", Separata del Boletín de la 
el colombiano Monroy Cabra ${ }^{16}$.

Tal, el estado del derecho convencional y de la doctrina de la región al abordarse el tratamiento de la materia por la Segunda Conferencia Especializada Interamericana de Derecho Internacional Privado, CIDIP $\mathrm{II}^{17}$.

\section{LAS SOLUCIONES ACTUALES}

\subsection{Las Convenciones Interamericanas y la aplicación e información del derecho extranjero}

La codificación de los principios generales de Derecho Internacional Privado iniciada a nivel regional, en lo que hace a textos efectivamente entrados en vigor, con el Protocolo Adicional a los Tratados de Montevideo de Derecho Internacional de 1889, alcanza su culminación con la Convención Interamericana de Montevideo de 1979 sobre Normas Generales de Derecho Internacional Privado ${ }^{18}$ que en sus artículos 2 y 4 atiende específicamente lo atinente a la aplicación del derecho extranjero y la recurribilidad de las sentencias dictadas en tales casos. En tanto que todo lo referido a la información del derecho foráneo es regulado por la Convención Interamericana de Montevideo de 1979 sobre Prueba e Información del Derecho Extranjero, también aprobada por la CIDIP II.

\subsubsection{Aplicación del derecho extranjero}

La Convención Interamericana sobre Normas Generales de Derecho Internacional Privado al disponer en el art. 2, "Los jueces y autoridades de los Estados estarán obligados a aplicar el derecho extranjero tal como lo harían los jueces del Estado cuyo derecho resulte aplicable...", si bien no utiliza la expresión "de oficio", consideramos que

Academia de Ciencias Políticas y Sociales de Venezuela, octubre - noviembre 1977, año XXXII, Caracas, p. 32.

16 MONROY CABRA M. G. (1972) Tratado de Derecho Internacional Privado. Bogotá, p. 532. 17 Por un panorama detallado sobre el tratamiento del derecho extranjero en el Uruguay y en la región en la época de aprobación de la Convención Interamericana sobre Normas Generales de Derecho Internacional Privado, ver TELLECHEA BERGMAN E. (1982) Derecho Internacional Privado y Derecho Procesal Internacional. Montevideo: Ediciones Jurídicas Amalio Fernández, p. 15-110.

18 Otras cuestiones asimismo vinculadas a la aplicación del Derecho indicado por la norma de conflicto reguladas por la Convención, son: institución desconocida, art. 3; orden público internacional, art. 5; fraude a la ley, art. 6; reconocimiento de situaciones jurídicas válidamente creadas en el extranjero de acuerdo a todas las leyes con las que tengan conexión al momento de su creación, art. 7; cuestión previa o incidental, art. 8; y aplicación armoniosa de las distintas leyes que puedan ser competentes para regular diferentes aspectos de una misma relación jurídica con miras a alcanzar la finalidad perseguida por cada una de dichas legislaciones, art. 9. 
consagra su aplicación preceptiva en coincidencia con sus precedentes directos, los arts. 2 de los Protocolos Adicionales a los Tratados de Montevideo de Derecho Internacional de 1889 y 1940 y 408 del Código de Bustamante, así como el art. 3 del Proyecto de Convención Interamericana elaborado por el Comité Jurídico Interamericano el 24.1.1978 como documento preparatorio de la CIDIP II $^{19}$ y los criterios acordados por las Primeras Jornadas Rioplatenses de Derecho Internacional celebradas en Montevideo en octubre de 1978 con finalidad de aunar posiciones con miras a la CIDIP $\mathrm{II}^{20}$. Alcance del art. 2 de la Convención, avalado tanto por el "Informe del Presidente del Grupo de Trabajo de la Comisión II de la Conferencia”, Dr. Mac Lean Ugarteche, Delegado de Perú ${ }^{21}$, como por el Presidente de dicha Comisión, Dr. Gonzalo Parra Aranguren, Delegado de Venezuela, que resaltara al respecto el consenso alcanzado "acerca del deber de juez de investigar y aplicar de oficio el derecho extranjero que resulte competente por mandato de la respectiva norma de Derecho Internacional Privado" 22 .

19 Art. 3, "La aplicación de las leyes de los Estados contratantes será hecha de oficio por el juez de la causa, sin perjuicio de que las partes puedan alegar y probar la existencia y contenido de la ley extranjera invocada".

20 Resolución de las 1ras. Jornadas Rioplatenses de Derecho Internacional, Montevideo, octubre de 1972: "Visto: Que el temario de la CIDIP II incluye el tratamiento de un proyecto sobre "Prueba del derecho extranjero e información sobre normas jurídicas vigentes en los Países Americanos"...

LAS PRIMERAS JORNADAS RIOPLATENSES DE DERECHO INTERNACIONAL RESUELVEN RECOMENDAR:

1) Se consagre en la Convención sobre Aplicación e Información del Derecho Extranjero, como principio básico, la aplicación de oficio del derecho extranjero, ratificándose de tal manera las soluciones contempladas en el Código de Bustamante de 1928 y los Protocolos Adicionales a los Tratados de Montevideo de 1889 y 1940.

2) Igualmente se acepte la facultad de las partes de colaborar con el Juez, ya sea en la forma de mera alegación del derecho foráneo, ya sea aportando información acerca del mismo.

3) Los jueces y autoridades administrativas puedan valerse de cuantos medios de averiguación del derecho extranjero consideren necesarios, dictando al efecto las providencias oportunas.

4) Sería indispensable que siguiéndose los lineamientos del Convenio sobre "Información en Materia Jurídica respecto del Derecho vigente y su Aplicación” adoptado por la II Conferencia de Ministros de Justicia de los Países Hispano Luso Americanos y Filipinas - ratificado entre otros por la República Argentina - los Estados Partes en la futura Convención de la O.E.A. centralicen la actividad de información sobre sus respectivos derechos en un órgano nacional especializado.

5) La información sobre el derecho vigente en cada país, especialmente la proporcionada por los órganos nacionales pertinentes, contenga, según el caso, las normas y sus fuentes, así como la jurisprudencia judicial y administrativa y doctrinas nacionales existentes.

6) Se promueva dentro del marco de la O.E.A., la creación de un Centro de Información sobre el derecho de los países de la región, a cuyos efectos cada Estado contratante se obligue a transmitir al mismo la información a que se refiere el apartado anterior, actual y futura.

7) Es conveniente que la futura Convención Interamericana, en forma expresa disponga que en la aplicación de la Ley extranjera debe estarse respecto a su interpretación, constitucionalidad, aplicación espacial, temporal y en todos los demás aspectos, a las soluciones dadas en el Estado al cual la norma pertenece.

8) Hacer llegar a las autoridades pertinentes las presentes conclusiones.

21 El informe aclara que el Grupo de Trabajo consideró que la aplicación debía hacerse de oficio, Documento CIDIP II/62, p. 3.

22 PARRA ARANGUREN G. (1982) Codificación del Derecho Internacional Privado en 
Interpretación del alcance del artículo confirmada por la pacífica aceptación de su tenor por Delegaciones de países que como Argentina, Brasil, Uruguay y Venezuela, sostuvieran firmemente en la Conferencia la aplicación de oficio del derecho foráneo.

En cuanto al alcance a otorgar a la expresión "derecho" utilizada por el art. 2, surge del "Informe del Relator de la Comisión II", Prof. Opertti, que el término fue empleado en sentido amplio, comprensivo no sólo de las normas escritas sino de todas las fuentes jurídicas de un ordenamiento ${ }^{23}$, tal como propusiéramos al respecto en la "Recomendación 5" de las Primeras Jornadas Rioplatenses de Derecho Internacional; en igual sentido, Tatiana B. de Maekelt ${ }^{24}$.

Este deber de las autoridades respecto a la aplicación del derecho extranjero, no inhibe la facultad de las partes de "alegar y probar" la "existencia y contenido" del mismo. Actividad informativa que no corresponde interpretar como sinónimo de una potestad probatoria capaz de restringir las parámetros dentro de los cuales puede moverse el magistrado, que siempre será titular del poder - deber de identificar y aplicar el derecho llamado a regular la situación jurídicamente relevante llevada a su conocimiento.

En relación al mandato de aplicar la norma ajena "tal como lo harían - con el sentido y el alcance - los jueces del Estado cuyo derecho resulte aplicable" 25 , debe tenerse presente en relación a países en los que su ordenamiento no consagra la obligatoriedad del precedente judicial, que los tribunales del Estado aplicador no deben conferir a las decisiones judiciales del ordenamiento de origen de la norma mayor autoridad que las que ellas tienen en dicho país ${ }^{26}$, por lo que corresponde concluir que el magistrado posee respecto al Derecho ajeno una libertad interpretativa no inferior a la de los tribunales del Estado al que dicha norma pertenezca. Al respecto, en un caso de aplicación por tribunales uruguayos de derecho chino, Opertti ha sostenido: "El juez uruguayo dispone de suyo, de por lo menos, igual libertad para fallar que el juez chino, pero en ningún caso menor a la de éste"27: Posición que compartimos y que enunciáramos hace ya años

América. Caracas: Universidad Central de Venezuela, Facultad de Ciencias Jurídicas y Políticas, p. 420; Idem, Documento CIDIPII/62, p. 4.

23 Informe del Relator, Documento CIDIPII/68, p. 4.

24 MAEKELT Tatiana B. de (1984) Normas Generales de Derecho Internacional Privado en América. Caracas: Universidad Central de Venezuela, Facultad de Ciencias Jurídicas y Políticas, pp. 154.

25 Mandato del que surge la importancia de proveer posibilidades ciertas de información a los aplicadores del Derecho extranjero. Como se verá, la Convención Interamericana sobre Prueba e Información del Derecho Extranjero cumple con tal finalidad permitiendo la efectiva aplicación del art. 2 de la Convención Interamericana sobre Normas Generales de Derecho Internacional Privado.

26 Conforme, entre otros, CIRYLLE D. (1965) La loi étrangere devant le juge du fond. París: Dalloz, p. 278.

27 Consulta emitida en el "caso Xiang - Cheng", transporte marítimo entre Uruguay y la 
Aplicación e información del derecho extranjero... Eduardo Tellechea Bergman

en nuestra obra, "Tratamiento e información del Derecho extranjero"28, al señalar: "El magistrado al interpretar la norma ajena, si bien debe atenerse a las pautas proporcionadas por el derecho referido sin poder alterar la jurisprudencia existente, no es un copista, sino que realiza una actividad necesariamente valorativa ..." "Esta necesidad de valorar la solución más adecuada se acentúa en el caso de que el sistema jurídico remitido esté fundado en un régimen de libertad jurisprudencial, donde de existir distintas soluciones respecto a una misma cuestión, la posibilidad de opción del foro será ciertamente aún mayor", pues como dice Aguilar Navarro"29 "el juzgador si bien debe afanarse por alcanzar una interpretación conforme con la que domina en el ordenamiento extranjero, ello no le priva de libertad de apreciación ....”

\subsubsection{Aplicación del derecho perteneciente a Estados con distintos sistemas jurídicos territoriales o personales}

En hipótesis en que la norma de conflicto señale para regular el caso un ordenamiento perteneciente a un país con diferentes sistemas jurídicos de base territorial, en consonancia con criterios generales ya enunciados en materia de aplicación del Derecho extranjero que imponen: "Los jueces y autoridades de los Estados Parte estarán obligados a aplicar el derecho extranjero tal como lo harían los jueces del Estado cuyo derecho resultare aplicable", Convención Interamericana de 1979 de Normas Generales de Derecho Internacional Privado, art. $2^{30}$, consideramos que tal como preveía la Recomendación $7^{\text {a }}$ de las Primeras Jornadas Rioplatenses de Derecho Internacional Privado, debe estarse a lo dispuesto por el ordenamiento del país cuyo derecho resulte aplicable a la especie en consideración ${ }^{31}$ y a falta de soluciones al respecto, a la legislación de la unidad territorial en que la conexión se realice. El Proyecto uruguayo de Ley General de DIPr., art. 2, "Aplicación del Derecho extranjero", acoge esta posición ${ }^{32}$. Los actuales desarrollos convencionales de La Haya también buscan resolver estas situaciones en base a similar criterio, así, la Convención de 19 de octubre de 1996 Relativa a la Competencia, la Ley Aplicable, el Reconocimiento, la Ejecución y la Cooperación en Materia de Responsabilidad Parentelar

República Popular China, Revista de Transporte y Seguros, № 10, p. 109.

28 TELLECHEA BERGMAN E., Op. cit., nota3, p. 43.

29 AGUILAR NAVARRO M. (1955) Derecho Internacional Privado, Tomo I, Parte General. Madrid: Ed. E. I. S.A., p. 433.

30 Solución coincidente con la del Código General del Proceso de Uruguay, art. 525.3.

31 Ver nota 20.

32 Proyecto de Ley General de Derecho Internacional Privado, art. 2, numeral 2: "Cuando el derecho extranjero corresponde a un Estado cuyo orden jurídico se compone de varias legislaciones, el derecho de ese Estado determina cual de ellas es aplicable. En su defecto debe aplicarse la legislación de la unidad territorial en cuya legislación se realiza el punto de conexión". 
y de Medidas de Protección de los Niños, aprobada por Uruguay por Ley 18.535 del 21.8.2009, art. 48 y el Protocolo sobre Ley Aplicable a las Obligaciones Alimenticias del 23.11.2007, art. 16, "Sistemas unificados de carácter territorial", numeral 2.

Asimismo, en situaciones en las que la remisión refiera al derecho de un país en el que dos o más sistemas normativos se apliquen a diferentes categorías de personas, de acuerdo a principios ya expuestos, sostenemos que de existir en dicho Estado soluciones que permitan identificar cual de dichos sistemas es el aplicable, deberá estarse a tales soluciones y en su defecto deberá acudirse al conjunto normativo con el cual el caso presente los vínculos más estrechos, tal lo resultante de la Convención de La Haya de 19.10.1996, art.49.

\subsubsection{La jurisprudencia nacional y la aplicación del derecho extranjero}

Los tribunales uruguayos en distintos fallos, tal el "caso Corrit"33, han concretado en la práctica judicial el mandato de que la normativa extranjera debe aplicarse e investigarse de oficio, sin perjuicio de los aportes informativos de las partes. En el caso de referencia, el tribunal que dictó el fallo definitivo basó sus conclusiones sobre el derecho extranjero aplicable - chino, en la especie - en sus propias investigaciones, sin perjuicio de los informes de los litigantes.

Entre casos jurisprudenciales más recientes, cabe citar el del "buque Uniforward", también vinculado a la aplicación de derecho chino, referido a un transporte marítimo entre Uruguay y China en el que el armador y transportista es demandado ante tribunales nacionales por incumplimiento de contrato y perjuicios derivados en relación a un embarque de noventa fardos de lana que llegan a destino con perjuicios por daños por mojadura. En la especie, el Tribunal de Apelaciones en lo Civil de 3er. Turno, integrado por los Dres. Julio Cesar Chalar,

33 El caso Corrit supuso una controversia acerca del valor en el Derecho uruguayo de un convenio de sociedad familiar universal de bienes celebrado en Shangai en 1946. El acuerdo involucraba al esposo, un dinamarqués residente en China y su esposa, una rusa exiliada, que se habían casado en Shangai ante el cónsul dinamarqués en 1927. Tiempo después y en razón del cambio institucional operado en China el matrimonio se radica en Uruguay, tramitado su separación conyugal en los años sesenta. Se plantea entonces ante tribunales nacionales y en relación al reclamo de disolución de la sociedad de bienes pactada, la cuestión de su validez. La esposa afirmaba el valor de la misma apoyándose en el derecho Chino de la época de constitución de la sociedad, en tanto que el marido lo negaba fundándose en el derecho dinamarqués que consideraba era el aplicable en razón de lo establecido en capitulaciones sino - dinamarquesas del siglo XIX, posteriormente denunciadas por China. La justicia uruguaya finalmente falló pronunciándose por el valor de dicha sociedad familiar y aplicó el derecho chino. El caso se planteó ante el Juzgado Letrado de Primera Instancia en lo Civil de 3er. Turno a cargo del Dr. R. Addiego Bruno, y en segunda instancia conoció el Tribunal de Apelaciones en lo Civil de 3er. Turno, Ministros, Dres. Torello, Reyes Terra e Igorra. Por más información sobre este caso, ver Revista Uruguaya de Derecho Internacional, (4), 1975/1976. 
Aplicación e información del derecho extranjero... Eduardo Tellechea Bergman

Bernandette Minvielle y Selva Klett, en sentencia definitiva № 171 del 15.9.1999 (redactora: Dra. Minvielle), falla considerando "aplicable la ley china de 7.11.92, en vigor desde el 1.7.93, tal como lo harían los tribunales de la República Popular de China" señalando al respecto, "Como enseña Batiffol, el magistrado actúa como un sociólogo, buscando no aquella solución que le pueda parecer justa, útil, sino por el contrario, tratando de establecer aquello que efectivamente es el derecho extranjero (Cfr: Droit International Privé, no 325, p. 381-382), concluyendo: "En su mérito, en la materia objeto de agravio, corresponde la aplicación de los arts. 56 y 44 del CMCh (cuya traducción obra a fs. 98-98 vta., y 95 vta. respectivamente), en tanto por el primero se fija un piso en el monto de las reparaciones acorde - por otra parte - con el principio de reparación integral del daño y por el segundo, se prohíben cláusulas que vulneren tal regla" 34 .

\subsubsection{El art. 2 de la Convención Interamericana sobre Normas Generales de Derecho Internacional Privado y el reenvío}

El mandato legislado por el artículo, referido a la obligación de aplicar el Derecho extranjero según lo aplican los tribunales del país de origen, ha sido interpretado por alguna doctrina como una implícita consagración del reenvío ${ }^{35}$. Entendemos, por el contrario, que tal como surge del propio texto aprobado y de sus antecedentes, se dejó de lado la regulación del instituto, pues mientras que Delegaciones como las de Venezuela y Argentina propugnaban por incluirlo, otras, como las de Uruguay y Brasil se oponían al mismo, por lo que ante la disparidad de criterios se convino en no tratar el tema ${ }^{36}$. Razón por la que cabe concluir que existe un silencio convencional que no puede interpretarse ni como aceptación ni como rechazo, sino como no regulación del instituto, quedando la cuestión librada a lo que dispongan los respectivos ordenamientos nacionales. $\mathrm{Al}$ respecto consideramos que en nuestro DIPr. vigente únicamente puede tener recepción el reenvío, de manera acotada y excepcional, en el ámbito de la hipótesis del art. 9 de la Convención Interamericana sobre Normas Generales de DIPr.,

34 Revista Uruguaya de Transporte y Seguros, (13), 2000, "Jurisprudencia anotada", con consulta de D. OPERTTI "Aplicación del Derecho Extranjero y Reenvío en el Derecho Internacional Privado uruguayo".

35 PARRA ARANGUREN G. (1979) "La Convención Interamericana sobre Normas Generales de DIPr. (Montevideo, 1979)". Anuario Jurídico Interamericano. Washington: OEA, p. 172, en relación al art. 2, dice: "por vía de consecuencia acepta el reenvío desde una perspectiva sociológica, es decir cuando se encuentre encapsulado en la solución fáctica extrajera que debe tratarse de reproducir"; en el mismo sentido, GOLDSCHMIDT W. (1979) "Normas Generales de la CIDIP II. Hacia una teoría general del derecho internacional privado interamericano". Anuario Jurídico Interamericano, Washington: OEA, p. 151.

36 Informe del Relator de la Comisión II de la CIDIP II, OPERTTI D. "Actas y Documentos" Segunda Conferencia Especializada Interamericana sobre DIPr, V.I. S/e, p. 290. 
búsqueda de la equidad del caso concreto ${ }^{37}$. El Proyecto uruguayo de Ley General de Derecho Internacional Privado, art. 12, "Reenvío", excluye en principio su aplicación, permitiendo su uso sólo en casos concretos con objeto de corregir un resultado incompatible con la finalidad de la norma de conflicto que señala el derecho aplicable y precisa además, que en materia contractual no habrá reenvío.

\subsubsection{Recurribilidad de los fallos dictados en error del derecho extranjero}

El art. 4 de la Convención sobre Normas Generales consagra la procedencia de todos los recursos previstos por la ley procesal del foro contra la errónea aplicación o interpretación del derecho local respecto a los casos en que corresponda la aplicación del derecho de las otras Partes. La norma, con antecedentes directos en los arts. 3 de los Protocolos a los Tratados de Montevideo de Derecho Internacional de 1889 y 1940 y 4 del Proyecto del Comité Jurídico Interamericano sobre normas Generales del DIPr., constituye una solución que juzgamos correcta, cuanto que resultan rechazables los argumentos esgrimidos para negar la recurribilidad de los fallos dictados en los casos en que corresponda aplicar derecho extranjero ${ }^{38}$.

Respecto a la procedencia del recurso de casación, atento a la finalidad que persigue, uniformizar y asegurar la correcta aplicación del derecho, su interposición no puede quedar limitada al estrecho recinto del derecho interno y debe alcanzar a todas las normas jurídicas, inclusive las extranjeras aplicables por mandato de las normas de conflicto, que no sólo deben ser aplicadas, sino además deben serlo en forma correcta $^{39}$. En posición concordante, G. Parra Aranguren, dice:

37 Ver en relación al tema, TELLECHEA BERGMAN E., Op. cit., nota 3, p. 47-49; también FRESNEDO DE AGUIRRE C. (2001) Curso de Derecho Internacional Privado - Parte General, T. I. Montevideo: F.C.U, p. 234-235.

38 Las razones invocadas para denegar la recurribilidad en estos casos varíen desde aquellas fundadas en una superada concepción fáctica del Derecho foráneo, a posiciones que sostienen que en tanto el principio "iura novit curia" no es de recibo en relación al Derecho ajeno al foro, no corresponde corregir los errores que cometan los tribunales inferiores, SALOMÉ Y. (1938) Le pouvoir de contrôle de la Cour de Cassation en matière de conflicts de lois. París: Librairie du Recueil Sirey, p. 141-142; o que dadas las dificultades que plantea la información del Derecho extranjero y el descrédito que acarrearía a los tribunales superiores una decisión desacertada, no debe admitirse dicha recurribilidad, NIBOYET J. P. (1948) Traité de Droit Internacional Privé français. París: Librairie du Recueil Sirey, p. 610-611. Posiciones en relación a las cuales decimos: respecto a la sostenida por Yvonne Salomé, que si bien es exacto - como ya se indicara - que el aplicador no está obligado a conocer de antemano el Derecho extranjero, tiene en cambio el deber de investigarlo e individualizarlo una vez planteado el caso y en la eventualidad que no lo aplique o lo haga incorrectamente, es lógico y necesario que la sentencia sea recurrible; y en relación al argumento de Niboyet, creemos que lo pertinente es dotar a los tribunales de los medios informativos adecuados para el cabal cumplimiento de sus cometidos y no proceder a la inversa, negando los recursos.

39 En coincidencia, D. OPERTTI, Doc. CIDIP II/62, p. 15. 
“parece indiscutible que el precepto - por el art. 4 de la Convención de Normas Generales - no pretende abandonar al ordenamiento jurídico de cada uno de los Estados Partes la admisibilidad del recurso de casación por infracción a la ley extranjera; y de acuerdo con sus propios términos equipara el derecho foráneo con las normas nacionales en los diversos aspectos relativos al funcionamiento del mencionado instituto; por tanto no sería aceptable que existirán regímenes distintos establecidos ad "libitum" en cada uno de los países vinculados por la Convención" 40 .

\subsubsection{Información del derecho extranjero}

En tanto la Convención Interamericana sobre Normas Generales de DIPr. desarrolla principios recibidos por textos anteriores consagrando la obligatoriedad para jueces y otras autoridades de los Estados de aplicar el derecho de los otras Partes con el sentido que tienen en el de origen, resultaba necesaria una regulación que proveyera de medios idóneos de información jurídica. La Convención Interamericana sobre Prueba e información del Derecho Extranjero da respuesta a tal necesidad.

Respecto a la expresión "prueba", término utilizado por la Convención en el título, acápite y en varios artículos, consideramos inconveniente su empleo, pues puede conducir al error que se interprete que el sistema interamericano se afilia a una concepción atributiva de índole fáctica al derecho extranjero, posición opuesta a aquella consagrada por el examinado art. 2 de la Convención Interamericana de Normas Generales. En la medida que esta Convención, que regula la teoría general del DIPr., concibe a la normativa ajena al foro como derecho, no corresponde en puridad hablar de "prueba", sino de "información" ${ }^{41}$. Textos convencionales de fecha posterior vigentes para nuestra República, han empleado correctamente el término "información" 42 .

El art. 2 de la Convención sobre Prueba e Información acerca del Derecho Extranjero precisa el alcance de los informes a proporcionar, señalando que los mismos pueden referir al "texto, sentido y alcance legal”. De lo que resulta que los datos no sólo pueden estar vinculados

40 PARRA ARANGUREN G., Op. cit., nota 35, p. 177.

41 En el mismo sentido, G. PARRA ARANGUREN, "El término prueba del derecho extranjero no es correcto, ya que se presta a confusiones porque alguien puede entender que el derecho extranjero es un elemento de hecho del proceso ... solución contraria a la aceptada por esta misma Conferencia en la Convención de Normas Generales", Doc. CIDIP II/82, p. 4.

42 Convenio bilateral sobre Aplicación e Información del Derecho Extranjero concluido con Argentina, aprobado por Decreto-ley 15.109 del 17.3.1981; Convenio de Cooperación Judicial uruguayo - brasileño del 9.2.1996, art. 24; Protocolo del Mercosur sobre Cooperación y Asistencia Jurisdiccional, Decisión CMC 05/92 y Acuerdo de Cooperación y Asistencia Jurisdiccional entre los Estados Parte del Mercosur y la República de Bolivia y la República de Chile, Decisión CMC 08/02, Capítulo VII, “Información del Derecho Extranjero", arts. 28 a 30 de ambos textos. 
al contenido de la norma, sino, además, a su aplicación en el tiempo, interpretación y relación jerárquica dentro del ordenamiento al que pertenece. Solución coherente con el mandato de aplicar el derecho extranjero como sus tribunales lo hacen.

\subsubsection{Medios de información}

Además de la admisión de todos aquellos procedimientos previstos tanto por la legislación del Estado requirente como el requerido, el art. 3 realiza una enumeración, no taxativa, de medios considerados como especialmente adecuados a los fines perseguidos ${ }^{43}$, sin que ello suponga una jerarquización de los mismos:

a) "prueba documental, consistente en copias certificadas de textos legales con indicación de su vigencia, o precedentes judiciales". Las copias de los textos legales constituyen un medio útil para conocer el contenido y vigencia de las normas, en tanto que los precedentes judiciales no sólo revisten especial significación para el conocimiento del derecho de países pertenecientes al common - law, sino que suponen un importante aporte para informar acerca de la interpretación y aplicación de la normativa de los Estados de derecho escrito. Estos medios siempre ha de resultar útil complementarlos por el previsto en el literal siguiente.

b) "prueba pericial consistente en dictámenes de abogados o expertos en la materia", procedimiento ya contemplado por el Código de Bustamante, art. 409, aun cuando en éste se reservara su empleo únicamente a las partes. La Convención Interamericana no contiene tal limitación y agrega como novedad, la posibilidad que el dictamen pueda ser hecho además de abogados, por "expertos", a los que no se exige la calidad de abogados, autorización que adquiere sentido si se piensa en juristas radicados en un país distinto a aquel en el que se graduaron y que por alguna razón no hubieren revalidado su título y que precisamente por su calidad de titulados en el extranjero, puedan resultar expertos en el derecho aplicable ${ }^{44}$.

En tanto la pericia proporcionada por los litigantes puede originar sospechas de parcialidad, es conveniente extremar controles que acrediten la calidad y autenticidad de los informes aportados.

c) "los informes del Estado requerido sobre el texto, vigencia, sentido y alcance legal de su derecho sobre determinados aspectos". Se trata del procedimiento informativo en derredor del cual gira en gran medida la Convención, habiéndose trasformado a nivel regional en el método más utilizado para informar con exactitud y objetividad acerca del derecho extranjero. Esta actividad a cargo del Estado exige

43 Tal lo expresado en la Conferencia al abordarse el tema, Doc. CIDIP II/82, p. 3.

44 Situación planteada por W. GOLDSCHMIDT al estudiarse el tema en la CIDIP II, Documento CIDIP II/82, p. 3. 
Aplicación e información del derecho extranjero... Eduardo Tellechea Bergman

la puesta en funcionamiento de organismos capaces de llevarla a cabo, las Autoridades Centrales ${ }^{45}$, dotándolas de personal técnico capacitado para el correcto cumplimiento de estos cometidos.

\subsubsection{Autoridades legitimadas para solicitar la información}

El art. 4, última parte, extiende a todas las autoridades la posibilidad de acceder a los medios informativos previstos en los literales a y $b$ del art. 3, pero de acuerdo a su párrafo primero, reserva el procedimiento indicado por el apartado $\mathrm{c}$ del art. 3, a las solicitudes provenientes de autoridades jurisdiccionales. Al respecto debe entenderse por tales no sólo las pertenecientes al Poder Judicial de un país sino todas aquellas que integren o no dicho Poder desarrollen actividad jurisdiccional, requisito que implica imprescindible independencia del órgano actuante y potestad para resolver con autoridad de cosa juzgada el litigio sometido a su conocimiento. El art. 4, párrafo segundo, admite que los Estados puedan extender a otras autoridades la posibilidad de acceder a la vía oficial, beneficiándolas así con el modo de información jurídica hoy más utilizado.

\subsubsection{El papel de las Autoridades Centrales en la información del derecho}

Las Autoridades Centrales en tanto organismos especializados a través de los cuales se presta la asistencia jurídica internacional, constituyen el centro de la información jurídica vía oficial, previendo la Convención a tales efectos que cada Estado designe su Autoridad Central, art. 9.

En Uruguay la Autoridad Central, creada en cumplimiento de diversos compromisos internacionales asumidos por la República que prevén su funcionamiento, está organizada por el Decreto 95/96 del 12.3.1996, que sustituyó al Decreto 407/85, y tiene a cargo entre sus cometidos, art. 4.a, "responder por sí o cometiendo la respuesta, las consultas provenientes de órganos competentes del exterior, acerca del Derecho interno e Internacional Privado de la República, así como aquellas provenientes de órganos públicos nacionales referidas al contenido y vigencia del Derecho Internacional Privado del país o de un Derecho extranjero".

Las comunicaciones cursadas a las Autoridades Centrales solicitando información jurídica, no requieren de legalización, Convención, art. 7.

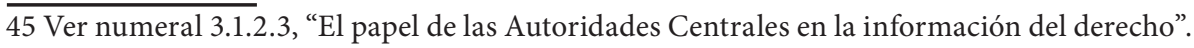




\subsubsection{Contenido de las solicitudes de información}

El pedido debe emanar de órgano jurisdiccional del país requirente o de otras autoridades, si los Estados así lo hubieren autorizado, de lo que surge que la Convención no legitima a los particulares para recurrir directamente a esta vía ${ }^{46}$ y debe ajustarse a determinados requisitos, art. 5, indicando:

a) "autoridad de la que provienen y naturaleza del asunto". La identificación de la autoridad requirente resulta imprescindible a efectos de asegurar que la solicitud emane de órgano legitimado para solicitarla, en principio, órgano jurisdiccional. En cuanto a la determinación de la "naturaleza del asunto", la calificación que hace el solicitante tiene valor meramente informativo, pues la Autoridad Central requerida debe informar sobre su derecho aplicable al caso concreto según lo harían sus jueces, tal como impone el mandato del art. 2 de la Convención Interamericana de Normas Generales.

b) "indicación precisa de los elementos probatorios que se solicitan". La exigencia permite asegurar una información exacta, capaz de satisfacer las posibles dudas del tribunal rogante acerca del derecho foráneo que debe aplicar - texto, vigencia y jurisprudencia - a la vez que evita al Estado informante una engorrosa y superflua labor de pesquisa de datos eventualmente ya conocidos por el peticionante.

c) "determinación de cada uno de los puntos a que se refiere la consulta con indicación del sentido y alcance de la misma, acompañada de una exposición de los hechos pertinentes para su debido comprensión". La condición tiene por finalidad dotar a la Autoridad Central requerida de medios imprescindibles para un adecuado conocimiento de la situación concreta sobre la cual deberá informar la normativa aplicable.

El art. 5 en su parte final exige a fin de asegurar la debida comprensión de la solicitud, que en casos en los que el idioma del Estado requirente sea diferente al del requerido, el pedido sea acompañado de una traducción al idioma del país que debe proporcionar el informe. La respuesta, en cambio, bastará que esté redactada en la lengua del Estado informante.

\subsubsection{Diligenciamiento de las solicitudes}

La Autoridad Central del Estado rogado proporcionará la información solicitada ya de manera directa, ya transmitiendo la consulta a "otros órganos del mismo Estado", art. 6, párrafo primero, de lo que resulta que la Convención no preve que las Autoridades Centrales

46 Ello no impide que los particulares puedan requerir en un proceso judicial que el tribunal actuante sea quien solicite información sobre derecho extranjero a través del sistema de Autoridades Centrales. 
Aplicación e información del derecho extranjero... Eduardo Tellechea Bergman

puedan acudir a efectos de obtener información jurídica a instituciones ajenas al Estado al que pertenecen. La contestación deberá efectuarse a través de la Autoridad Central rogada, por lo que de recurrir ésta a otros órganos para evacuar la consulta, éstos necesariamente deberán remitir su informe a su Autoridad Central para que sea ésta quien la haga llegar a la Autoridad Central o tribunal extranjero requirente.

El Estado requerido "deberá responder a cada uno de los puntos consultados conforme a lo solicitado y en la forma más completa posible", art. 5, párrafo segundo, por lo que la Autoridad Central deberá proporcionar una respuesta detallada, que asegure la efectiva aplicación por las autoridades de un país del derecho del otro, tal como lo harían los jueces de dicho Estado.

\subsubsection{Excepciones a la obligatoriedad de respuesta}

La obligación de responder reconoce como límite los casos en que la contestación afecte "los intereses", "seguridad o soberanía" del país requerido, art. 10. La disposición supuso un cambio significativo respecto a la fórmula en principio manejada, que para lograr simulares propósitos acudía equivocadamente al concepto de orden público internacional, cuando en realidad esta excepción actúa en contra de la aplicación de un derecho extranjero que ofenda de manera grave y concreta principios esenciales del ordenamiento jurídico del foro, pero no respeto al deber de informar acerca del derecho propio. Cabe señalar que en la práctica de la Autoridad Central uruguaya no se han registrado casos en que se hayan invocado excepciones para denegar información de la normativa nacional solicitada.

La Convención no establece plazos dentro de los cuales la Autoridad Central requerida deba responder; no obstante el deber de cumplir de buena fe con la obligación de informar, impone hacerlo en el plazo más breve posible.

\subsubsection{Efectos de la respuesta}

La contestación carece de obligatoriedad tanto para el Estado emisor, cuanto para el que la recibe, art. 6, párrafos 2 y 3. La previsión referida a que la respuesta no obliga al Estado emisor a aplicar su Derecho de acuerdo a lo informado, clásica en la materia ${ }^{47}$, evita graves inconvenientes que para el sistema judicial de un país devendrían de dictámenes jurídicos emanados de órganos administrativos que

47 Ya recibida por la Convención de Londres de 1968 sobre Información del Derecho Extranjero y reafirmada a nivel del Mercosur por el Protocolo de Cooperación y Asistencia Jurisdiccional, Decisión CMC 05/92 y el Acuerdo espejo entre los Estados Partes del Mercosur y la República de Bolivia y la República de Chile, Decisión CMC 08/02, Capítulos VII, "Información del Derecho Extranjero", arts. 30 de ambos textos. 
pudieren obligar a su jurisprudencia.

En cuanto al carácter no vinculante de la respuesta para el Estado que la recibe, ello no supone mengua alguna al principio referido a que la aplicación y valoración del Derecho ajeno al foro debe hacerse de acuerdo al ordenamiento de origen, sino que tiene por finalidad asegura la libertad valorativa del tribunal requirente de la información, que podrá dejar de lado aquella obtenida vía oficial cuando de acuerdo a su propia investigación o al aporte de los litigantes considere que el verdadero contenido o interpretación de la norma ajena no se ajusta al que se le ha informado.

\subsection{Otros convenios multilaterales con disposiciones atinentes a la aplicación e información del derecho extranjero}

\subsubsection{Protocolo de Cooperación y Asistencia Jurisdiccional en Materia Civil, Comercial, Laboral y Administrativa entre los Estados Parte del Mercosur, Decisión CMC 05/92, Capítulo VII, "Información del Derecho Extranjero", arts. 28 a 30}

En tanto tema atinente al ámbito de la cooperación jurisdiccional internacional, el Protocolo atiende lo referido a la información del derecho de un Estado Parte a los otros adjudicando dicho cometido a las Autoridades Centrales, art. 28, aun cuando también prevé que tales datos puedan brindarse a través de las autoridades diplomáticas o consulares del Estado cuyo derecho es informado, art. 29. La no obligatoriedad de la información tanto para el país que la brinda, cuanto para el que la recibe, art. 30, responde a parámetros similares a los establecidos en el ámbito interamericano.

Dado que los Estados Parte del Mercosur son a su vez Parte de la Convención Interamericana sobre Prueba e Información del Derecho Extranjero $^{48}$, además de la información vía oficial prevista por el Protocolo, siempre podrá acreditarse el derecho de los demás países por cualquiera de los demás procedimientos previstos por la Convención, hoy el texto en la región más aplicado en la materia.

El Acuerdo de Cooperación y Asistencia Jurisdiccional en Materia Civil, Comercial, Labora y Administrativa entre los Estados Parte del Mercosur y la República de Bolivia y la República de Chile, Decisión CMC 08/02, reproduce las soluciones consagradas por el Protocolo del Mercosur.

\subsubsection{Convenios en materia de minoridad y familia}

48 Los Estados Partes del Mercosur, como se ha visto, son también Estados Parte de la Convención Interamericana sobre Normas Generales de Derecho Internacional Privado, que en los arts. 2 y 4 regula el tema de la aplicación del Derecho extranjero. 
Aplicación e información del derecho extranjero... Eduardo Tellechea Bergman

Distintos acuerdos referidos a la protección internacional de los niños y a las relaciones de familia contienen regulaciones específicas sobre información del Derecho.

En materia de restitución internacional de menores ilícitamente trasladados o retenidos fuera del Estado de su residencia habitual, la Convención de La Haya del 25.10.1980 sobre Aspectos Civiles de la Sustracción Internacional de Menores, art. 7.e y la Convención Interamericana de Montevideo de 1989 sobre Restitución Internacional de Menores, art. 9.1.c, contemplan que las solicitudes de restitución informen acerca del derecho en que se funda el pedido.

En lo relativo a la prestación internacional de alimentos, la Convención de Naciones Unidas de Nueva York del 20.6.1956 sobre Obtención de Alimentos en el Extranjero, art. 3, "Solicitud a la autoridad remitente", numeral 2, exige que cada Estado Parte informe a la Secretaría General acerca de los elementos de prueba normalmente requeridos por su legislación para fundar la demanda, el modo como deben ser presentados y cualquier otro requisito que de acuerdo a su derecho deba ser satisfecho. En igual sentido la Convención de La Haya sobre Cobro Internacional de Alimentos para los Niños y Otros Miembros de la Familia del 23.11.2007, en el art. 57, numeral 1.a, "Información relativa a leyes, procedimientos y servicios", dispone que los Estados al momento del depósito de los instrumentos de ratificación o adhesión proporcionen a la Oficina Permanente de la Conferencia una descripción de su legislación y de los procedimientos aplicables en materia de alimentos.

\subsection{El Código General del Proceso de Uruguay y el Proyecto de Ley General de Derecho Internacional Privado}

El Código, Libro Segundo, Título X, "Normas Procesales Internacionales", Capítulo I, "Principios Generales, consagra la aplicación de oficio del derecho extranjero y su interpretación tal como lo harían los tribunales a cuyo ordenamiento pertenezca la norma, así como la recurribilidad de las decisiones dictadas en tales casos, art. 525 , numerales 3 y 4 . Regulaciones aplicables en defecto de tratado o convención, art. 524, que transitan la línea de los textos convencionales ratificados por la República en la materia.

$\mathrm{El}$ art. 525.3 al disponer además de la aplicación de oficio, que las partes puedan "acreditar la existencia, vigencia y contenido de la ley extranjera”, párrafo segundo, no sólo atiende la cuestión de la aplicación del derecho foráneo sino también lo referido a su información. Cuestión también abordada por el Código en el art. 143, "Prueba del derecho", que más allá de lo criticable de su título al referir a "prueba", consagra el criterio correcto al disponer: "El derecho a aplicar, sea nacional o 
extranjero, no requiere prueba y el tribunal y las partes podrán acudir a todo procedimiento legítimo para acreditarlo". Solución amplia, que permite al juez un adecuado margen para informarse del contenido de la norma foránea y cumplir de este modo con el deber de aplicarlo tal como lo harían los tribunales de origen.

El numeral 4 del art. 525 agrega que todos los recursos previstos por la legislación nacional deben ser admitidos en los casos en que proceda la aplicación de un derecho ajeno al foro. Recurribilidad que abarca, como se señalara, la procedencia del recurso de casación, cuanto que las razones que fundan el mismo, art. 270 del C.G.P., "infracción o errónea aplicación de la norma de derecho", también se dan cuando no se aplica o se aplica incorrectamente el derecho extranjero señalado por la norma de conflicto para regular el caso.

De manera coincidente el Proyecto uruguayo de Ley General de Derecho Internacional Privado, Título I, "Normas Generales", art. 2, "Aplicación del derecho extranjero", numeral 1, acoge los principios básicos en el tema y dispone que éste debe ser aplicado de oficio e interpretarse tal como harían los tribunales del Estado a cuyo orden jurídico pertenece la norma respectiva, agregando que si el derecho extranjero corresponde a un Estado cuyo ordenamiento se compone de varias legislaciones, "el derecho de ese Estado determina cuál de ellas es aplicable" y en su defecto, "debe aplicarse la legislación de la unidad territorial en cuya jurisdicción se realiza el punto de conexión". Y en materia de recurribilidad, el art. 4, "Admisión de recursos procesales", dispone de manera amplia que "Cuando corresponda aplicar derecho extranjero, se admitirán todos los recursos previstos por la ley nacional". En tanto que en relación al "Conocimiento del derecho extranjero", el art. 3 prevé: "El texto, la vigencia, la interpretación del derecho extranjero aplicable deben ser investigados y determinados de oficio por las autoridades competentes, sin perjuicio de la colaboración que al respecto presten las partes o los interesados en el caso", agregando en el numeral 2 que a tales efectos, "se puede recurrir a todos los medios idóneos admitidos en el orden jurídico de la República o del Estado cuyo derecho resulte aplicable". La información jurídica deberá ser interpretada por los tribunales y demás autoridades en la forma cómo lo harían los tribunales del país de origen de la norma, art. 3, numeral 3.

Cabe agregar que en la investigación del derecho foráneo los tribunales uruguayos actuantes podrán recurrir siempre, aún en casos de inexistencia de tratados vigentes en la materia con el país de origen de la norma, a solicitar información a la Autoridad Central de Cooperación Jurídica Internacional, Decreto 95/96 del 12.3.1996, art. 4.a. La Autoridad Central requerirá directamente la información a su similar del Estado cuyo Derecho resulte aplicable si existiere tratado vigente que prevea esta posibilidad y en caso contrario, la información 
Aplicación e información del derecho extranjero... Eduardo Tellechea Bergman

será solicitada a través del Ministerio de Relaciones Exteriores de la República, el que oportunamente hará llegar a la Autoridad Central el informe recibido del exterior.

Tal, el panorama acerca de la aplicación y tratamiento del derecho extranjero a nivel interamericano, regional y en el DIPr. uruguayo.

\section{REFERENCIAS BIBLIOGRÁFICAS}

AGUILAR NAVARRO Mariano (1955) Derecho Internacional Privado, T.I - Parte General. Madrid:E.I.S.A.

ALFONSÍN Quintín (1955) Teoría del Derecho Privado Internacional. Montevideo: Biblioteca de Publicaciones de la Facultad de Derecho y Ciencias Sociales de la Universidad de la República.

ARAUJO Nadia de (2006) Direito Internacional Privado - Teoria e Prática Brasileira. Río de Janeiro: Renovar.

ARMINJON Pierre (1928) "L'Objet et le méthode du Droit International Privé”. Recueil des Cours. T. 21- I, p. 429-512.

AUDIT Bernard (2010) Droit International Privé. 6ta. ed. París: Económica.

BATIFFOL Henri (1959) Traité Élémentaire de Droit International Privé. París: Librairie Générale de Droit et de Jurisprudence.

BATIFFOL Henri (1976) "Conflits de lois dans l'espace et conflits de lois dans le temps”. En Choix D'Articles Rassemblés par ses Amis. París: Librairie Générale de Droit et de Jurispudence.

BUSTAMANTE Y SIRVÉN Antonio Sánchez de (1929) El Código de Derecho Internacional Privado y la Sexta Conferencia Interamericana. La Habana: Imp. Avisador Comercial.

CALVO CARAVACA Alfonso Luis (1987) "Problemas de Aplicación de las Normas Derecho Internacional Privado”. En PÉREZ VERA Elisa (coord.) Derecho Internacional Privado. Madrid: UNED, p. 137 -160.

CAPELLETTI Mauro (1968) El valor de las sentencias y de las normas extranjeras en el proceso civil. Buenos Aires. EJEA.

CIRYLLE David (1965) La loi étrangere devant le juge du fond. París: Dalloz.

FELDSTEIN DE CÁRDENAS Sara (1994) Reformas al Código Civil. Derecho Internacional Privado. Buenos Aires: Abeledo - Perrot.

FERNÁNDEZ ROSAS José Carlos y SÁNCHEZ Lorenzo Sixto (2007) Derecho Internacional Privado. Madrid: Thomson - Civitas.

FOELIX Jean Jacques Gaspard (1866) Traité du Droit International Privé ou du Conflit des Lois de Différentes Nations en Matière de Droit Privé. 4ta. ed. París: Marescq.

FRANCESKAKIS Phocion (1958) La théorie du renvoi et les conflits de systemes en droit international privé. París: Sirey.

FRESNEDO DE AGUIRRE Cecilia (1997) "Aplicación del Derecho Extranjero: sentido y alcance del art. 525.3 CGP”. Revista de Transporte 
y Seguros, (10), p. 116-124.

FRESNEDO DE AGUIRRE Cecilia (2001) Curso de Derecho Internacional Privado, T. I, Parte General. Montevideo: FCU.

GALLINAL Rafael (1916) Estudios sobre el Código de Procedimiento Civil - De las Pruebas. Comentarios a los artículos 327 a 349. Montevideo: Barreiro y Ramos.

GOLDSCHMIDT Werner (1935) La consecuencia jurídica de la norma de derecho internacional privado. Barcelona: Bosch.

GOLDSCHMIDT Werner (1979) "Normas Generales de la CIDIP - II. Hacia una teoría general del derecho internacional privado interamericano". En Anuario Jurídico Interamericano, Vol. 1979, p.141155.

GOLDSCHMIDT Werner (1974) Derecho Internacional Privado. Derecho de la tolerancia. 2da. Buenos Aires: Depalma.

MAEKELT Tatiana B. de (1984) Normas Generales de Derecho Internacional Privado en América. Caracas: Universidad Central de Venezuela - Facultad de Ciencias Jurídicas y Políticas.

MAEKELT Tatiana B. de (2005) "Aplicación del Derecho Extranjero". En MAEKELT Tatiana B. de, VILLAROEL Ivette Esis, RESENDE Carla (coord.) Ley de Derecho Internacional Privado Comentada, T. 1. Caracas: Universidad Central de Venezuela - Facultad de Ciencias Jurídicas y Políticas.

MANCINI Pascual Estanislao (1874) "De la utilité de rendre obligatoires pour touts les États, sous la forme d'un ou de plusiers traités internationaux, un certain nombre de régles générales de droit international privé pour assurer la décision uniforme des conflits entre les différentes législations civiles et criminelles". Journal de Droit International Privé, 1(1), p. 221-239, 285-304.

MAURY Jacques (1949) Derecho Internacional Privado. Puebla: José M. Cajica.

MAYER Pierre (1977) Droit International Privé. París: Editions Montchrestien.

MIAJA DE LA MUELA Adolfo (1976) Derecho Internacional Privado, T.I, Introducción y Parte General. Madrid: Ediciones ATLAS.

MONROY CABRA M. G. (1972) Tratado de Derecho Internacional Privado. Bogotá

MORELLI Gaetano (1953) Derecho Procesal Civil Internacional. Buenos Aires: EJEA.

MOTULSKY Henri (1960) "L'office de juge et la loi étrangere". En MAURY J. (edit.) Mélanges offerts a. París: Dalloz-Sirey, p. 337-375.

NIBOYET Jean Paulin (1948) Traité de Droit International Privé français. París: Librairie du Recueil Sirey.

NUSSBAUM Arthur (1947) Principios de Derecho Internacional Privado. Buenos Aires: Depalma. 
Aplicación e información del derecho extranjero... Eduardo Tellechea Bergman

OPERTTI BADÁN Didier (1980) "Informe del Relator de la Comisión II Referente al Tema Normas Generales de Derecho Internacional Privado". En SECRETARÍA JURÍDICA DE LOS ESTADOS AMERICANOS (edit.) Actas y Documentos Segunda Conferencia Especializada Interamericana sobre Derecho Internacional Privado (CIDIP II), Vol. I. Secretaría Jurídica de los Estados Americanos.

OPERTTI BADÁN Didier (1997) "Ley Aplicable y Pautas Paras la Aplicación de un Derecho Extranjero". Revista de Transporte y Seguros, (10), p.100-110.

OPERTTI BADÁN Didier (2000) “Aplicación del Derecho Extranjero y Reenvío en el Derecho Internacional Privado Uruguayo". Revista de Transporte y Seguros, (13), p.169 174.

PARRA ARANGUREN Gonzalo (1979) "La Convención Interamericana sobre Normas Generales de DIPr. (Montevideo 1979)". Anuario Jurídico interamericano, Vol. 1979, p. 157-186.

PARRA ARANGUREN Gonzalo (1982) Codificación del Derecho Internacional Privado en América. Caracas: Universidad Central de Venezuela - Facultad de Ciencias Jurídicas y Políticas.

RAMÍREZ Gonzalo (1888) Proyecto de Código de Derecho internacional Privado y su Comentario. Buenos Aires: Félix Lajouane.

RIGAUX Francois (1985) Derecho Internacional Privado. Parte General. Madrid: Civitas.

RUIZ DÍAZ LABRANO Roberto (1992) La aplicación de las leyes extranjeras y su efecto frente al derecho. Asunción: Intercontinental Editora.

SALOMÉ Yvonne (1938) Le pouvoire de contrôle de la Cour de Cassation en matière de conflits de lois. París: Librairie du Recueil Sirey.

SATTA Salvatore (1955) "Iuria novit curia". Rivista Trimestrale de Diritto e Procedura Civile, IX, p.380-401.

SAVIGNY Carlos Federico De (1879) Sistema de Derecho Romano Actual, T. VI. Madrid: F. Góngora y Compañía.

SOLARI BARRANDEGUY Marcelo (1978) "Prueba del derecho extranjero e información sobre normas jurídicas vigentes en los países americanos". En Primeras Jornadas Rioplatenses de Derecho Internacional. Montevideo. FCU, p.53-61.

SOTO Alfredo Mario (2001) Derecho Internacional Privado. La Importación del Derecho Extranjero. Buenos Aires: Ciudad Argentina.

TELLECHEA BERGMAN Eduardo (1978) "Cuestiones procesales relativas a la aplicación de la ley extranjera". En Primeras Jornadas Rioplatenses de Derecho Internacional. Montevideo: FCU, p.33-51.

TELLECHEA BERGMAN E. (1980) Tratamiento e Información del Derecho extranjero. Montevideo: FCU.

TELLECHEA BERGMAN Eduardo (1982) Derecho Internacional Privado y Derecho Procesal Internacional. Montevideo: Ediciones 
Jurídicas Amalio Fernández.

TELLECHEA BERGMAN Eduardo (2010) Derecho Internacional Privado. Montevideo: La Ley Uruguay

VALLADAO H. (1980) Direito Internacional Privado. Río de Janeiro: Biblioteca Jurídica Freitas Bastos.

VICO Carlos (1935) Curso de Derecho Internacional Privado. Buenos Aires: Biblioteca Jurídica Argentina.

YASSEN Mustafá Kamil (1962) "Problèmes relatifs à l'application du doit étranger”. Recueil des Cours, T. 106 - II, p. 499-596.

ZAJTAY Imre (1958) Contribution à l'étude de la condition de la loi étranger en Droit International Privé français. París: Pedone. 